\title{
La manifestación de la voluntad en los contratos como elemento fundamental para celebrarlos
}

\author{
The manifestation of the will in the contracts as a fundamental element to celebrate \\ them
}

ROBERTO-SANROMÁN, Aranda†

Universidad Autónoma del Estado de México. CU UAEM Valle de México

ID $1^{\mathrm{er}}$ Autor: Aranda, Roberto-Sanromán / ORC ID: 0000 0002-0682-6343

DOI: $10.35429 / J L A .2019 .10 .3 .27 .34$

Recibido 10 de Octubre, 2019; Aceptado 23 de Diciembre, 2019

\begin{abstract}
Resumen
La voluntad se forma a través de la inteligencia, mediante el proceso en el que el ser humano toma decisiones de manera libre y en las mismas se crean actos jurídicos, dentro de los que destacamos a los contratos. En el campo del derecho la persona, mediante el acuerdo de voluntades manifiesta el consentimiento, por medio de la palabra, la escritura o la tecnología, para celebrar distintos contratos, en los que se dan obligaciones de dar o de hacer, no hacer, dependiendo del contrato en que nos encontremos. Toda persona al celebrar un contrato debe estar libre de los vicios del consentimiento, ya sea error, dolo, mala fe, violencia, incapacidad o lesión. Y como consecuencia se producirán derechos y obligaciones para ambos contratantes, actuando en el campo del derecho de modo consciente y libre. La interpretación busca desentrañar el significado de lo establecido en un contrato, por lo que será necesario ir al pie de la letra, es decir, la expresión textual y, en caso de duda, a la intención de las partes contratantes
\end{abstract}

Manifestación, Voluntad, Derecho, Contrato, Interpretación

\begin{abstract}
The will is formed through intelligence, through the process in which the human being makes decisions freely and in them legal acts are created, within which we highlight contracts. In the field of law, the person, by means of the agreement of wills, expresses the consent, through the word, the deed or the technology, to celebrate different contracts, in which there are obligations to give or to do, not to do, depending on the contract in that we meet. Every person when entering into a contract must be free from the defects of consent, be it error, intent, bad faith, violence, disability or injury. And as a consequence, rights and obligations will be produced for both contractors, acting in the field of law in a conscious and free way. The interpretation seeks to unravel the meaning of what is stated in a contract, so it will be necessary to go to the letter, that is to say, the textual expression and in case of doubt to the intention of the contracting parties.
\end{abstract}

Manifestation, Will, Law, Contract,
Interpretation 


\section{Introducción}

En la presente investigación comenzaremos hablando sobre el significado del término manifestación, como medio de exteriorizar la voluntad, para continuar con el consentimiento, mediante dicho acuerdo de voluntades, parar producir efectos y consecuencias jurídicos. Una vez comprendido el consentimiento veremos lo importante que es para la celebración de los distintos tipos de contratos, para crear así relaciones jurídicas en el campo del derecho, sea mediante intercambio de bienes o servicios, según sea el caso, de una compraventa o la prestación de servicios profesionales, o de cualquier otro contrato.

También analizaré lo trascendental que es la libertad para contratar, y la ausencia de los vicios del consentimiento, -ya sea error, dolo, mala fe, violencia o lesión-. En el que debe haber el acuerdo de voluntades, de modo consciente y razonado, parar producir distintas consecuencias jurídicas.

Dentro del contenido de la investigación, afirmaremos y analizaremos, en principio que debe existir claridad en el contenido de un contrato, es decir en el texto plasmado, que sea manifestado lo que realmente las partes quisieron, es decir la voluntad interna sea conforme a lo exteriorizado, en caso de duda se deberá interpretar el contrato, primero conforme a la letra y si existe duda se estará a la intención de las partes.

Es importante cuestionarse las siguientes preguntas:

¿La voluntad es un elemento fundamental en el consentimiento? ¿Qué sucedería si el consentimiento no fuera libre al momento de manifestarlo en un contrato? ¿Por qué es importante conocer las distintas maneras de manifestar el consentimiento? ¿A falta de claridad en el contrato se podrá dar la nulidad del mismo?

El tema será tratado de manera general,
posteriormente analizar aspectos particulares. Dependiendo de las necesidades que se den a lo largo de la investigación.
Lo significativo es dar respuesta a las interrogantes planteadas y dejar las puertas abiertas para futuras investigaciones $\mathrm{u}$ otros cuestionamientos que se pudieren hacer los lectores. Posteriormente, plasmaremos algunas conclusiones, para terminar con una oportuna bibliografía.

\section{De la manifestación de la voluntad y el consentimiento en los contratos}

La palabra voluntad ha tenido distintos significados, pudiendo referirse al libre albedrío, pero para efectos de la materia que nos ocupa, "desde el punto de vista del derecho privado, el término refiere a la intención,- de alguna manera exteriorizada -de un sujeto que intenta la consecución de determinados efectos jurídicos. (...) una facultad compleja e intrincada que el sujeto posee en su consideración exclusiva como tal. (...) Para el jurista, la voluntad adquiere relevancia cuando, culminado el iter voluntatis, se inicia, entonces el proceso formal externo que concluye en un comportamiento o conducta verificable y fácilmente medible sus repercusiones sociales y, por ende jurídicas." (Diccionario Jurídico Mexicano, 1991, pp. 3256-3257)

Una vez que se ha definido la palabra voluntad, desde el punto de vista del derecho privado, nos abocaremos a dilucidar el término manifestación, que significa exteriorizar y para el caso de los contratos se refiere a que la voluntad interna de una persona se expresa o lleva a cabo a través de actos o hechos que lo presuponen, indudablemente en este supuesto debe coincidir lo que pensamos de manera interna con lo que expresamos por medio de la palabra, la escritura, a través de los medios tecnológicos, o hechos que se dan a entender de determinada manera, estos últimos pueden ser las prácticas compraventas que se realizan en las tiendas de autoservicio, en los que una persona al llegar con la cajera(o) deja el producto sobre el mostrador y paga el precio, muchas veces sin ni siquiera intercambiar alguna palabra con el empleado(a) que lo atiende, ya que tácitamente se está consintiendo, por hechos que lo presuponen y en dicha compraventa existe cosa y precio, siendo el contrato plenamente válido.

En el día a día realizamos muchas actividades de modo personal, por medios electrónicos o tecnológicos, por correspondencia, entre otras formas.

ROBERTO-SANROMÁN, Aranda. La manifestación de la voluntad en los contratos como elemento fundamental para celebrarlos. Revista de Aplicaciones del Derecho. 2019 
Por lo que de alguna manera debe quedar claro y sin lugar a dudas lo que realmente queremos expresar, ya que en esa medida el acto jurídico que realicemos tendrá un final exitoso o feliz y cumplirá con los requerimientos de ambos contratantes.

A través de la comunicación en la que existe un emisor, o llamado oferente, para el tema que nos ocupa al realizar un contrato y un receptor o aceptante para el pleno acuerdo de voluntades. Desde el momento en que pensamos en una idea que la convertiremos en determinado concepto, deberá existir una lógica, y en el supuesto planteado será jurídica, es decir, que exista congruencia en el pensamiento y en las ideas que han de ser armónicas, para con ello exteriorizarlas en el sentido más claro, correcto y de modo libre, por lo que la voluntad o el albedrío se unirá con otra voluntad para realizar dicho acuerdo que produzca los efectos jurídicos deseados.

De conformidad con lo anterior, la persona o sujeto debe tener capacidad mental para realizar el acto jurídico, denominado en el texto que estamos tratando, contrato y con ello realizar una obligación de dar o de hacer, o de no hacer dependiendo del tipo de contrato, es decir, si hablamos de una compraventa será de dar, y si nos encontramos en la prestación de servicios profesionales sería una obligación de hacer, y para el caso de una obligación de no hacer, ésta podría darse en un pacto de exclusiva en donde se puede limitar la venta de cualquier objeto a determinada persona; aplicables estas obligaciones a todos los contratos existentes en las leyes respectivas o los acordados por las partes, de conformidad con la autonomía de la voluntad en los contratantes y que no sea contrarío a la ley, lo pactado en el contrato respectivo.

Debemos entender por dicha libertad de los contratantes, que:" En principio, los particulares son libres para realizar negocios jurídicos y para regular como mejor les plazca, sus relaciones en el campo del Derecho privado. En términos generales, esta libertad para obligarse por propia decisión se conoce como autonomía de la voluntad. (Galindo, 1976, p. 243).
Los actos jurídicos, dentro de los que encontramos los contratos, tienen su nacimiento, en la voluntad de los particulares, en el caso que hablemos de contratos de naturaleza civil, - ya que también existen contratos en materia administrativa, en los que interviene el Estado,; o materia mercantil, al realizarlos entre comerciantes $o$ un comerciante y un particular, entre otros; sin embargo tanto los contratos administrativos como los mercantiles tienen su base en el derecho civil, es decir, no encontraremos el concepto de contrato en el Código de Comercio, sino en el Código Civil Federal, entre otros aspectos; mismos que son tratados por el derecho administrativo, para los primeros o el derecho mercantil para los segundos, con sus respectivas características- ; empero la autonomía de la voluntad rige en el derecho privado.

La gran mayoría de las relaciones jurídicas son de contenido patrimonial y dichos actos jurídicos que se producen deben contar con elementos de existencia y requisitos de validez, de conformidad con lo establecido en el Código Civil, Federal o Locales, según sea el caso para el supuesto que estamos tratando, es decir de la manifestación de la voluntad que hacen los contratantes en el momento que otorgan el consentimiento en los contratos realizados.

A lo largo de la historia hemos visto que las personas acuerdan desde la forma más primitiva al haberse realizado determinados rituales, como fue el caso de un contrato celebrado entre dos romanos, o por la simple palabra, en algunos casos por hechos que lo presuponen, hasta llegar a los medios tecnológicos o electrónicos, en los que se van conociendo diferentes avances en la técnica, es decir desde el correo electrónico, hasta el llamado WhatsApp, la sofisticación de dichos medios ha sido impactante, sobre todo la cantidad y la rapidez con la que se dan. Y en muchos casos son más seguros, como en el supuesto de las transacciones bancarias en las que se contienen medidas de seguridad, dentro de los que destacan, el Pas Word, el Número de Identificación Personal (NIP), la encriptación del mensaje, la huella digital, a través de la voz contenida en un medio tecnológico, por referirnos a algunos. 
Un aspecto importante de mencionar, es que la confianza que exista entre los contratantes al momento de manifestar la voluntad influye positivamente en la operación. Desde que el oferente y el receptor, es decir los contratantes acuerdan, deben tener apertura en el inicio de las negociaciones, ya que en muchas ocasiones prejuzgamos a las personas $\mathrm{y}$ esto afecta a las negociaciones, desde su inicio puede existir un rompimiento intempestivo, sin alguna causa justificada, incluso mal intencionada, por ello es importante tener mente abierta, pero claro está con las precauciones debidas, sin caer en los excesos, de la desconfianza o la confianza desmedida, salvaguardando la buena fe. "Confianza no quiere decir que se supervalore la apariencia, sino más bien protección de la buena fe.

Hoy, el principio de la buena fe ha llegado a ser general en el derecho, es un requisito propio del obrar humano, como se ha dicho; el que obra de buena fe, fiándose de cuanto aparece según las manifestaciones de otro, debe ser protegido. Pero buena fe no es supina ignorancia, así como confianza no es ciega entrega. Dichos principios, persiguen únicamente la salvo guarda del tercero que haya sido diligente en el conocimiento del negocio y sus circunstancias.

La tutela o protección de la confianza, responde a un criterio general en el que se inspira el legislador, y no está solamente previsto para superar el conflicto entre la voluntad y su manifestación." (Trabucchi, 1967, p.208)

Un aspecto a considerar se refiere a que en el momento de exteriorizar la voluntad, debemos tener presente el enfoque jurídico del contrato que realizaremos, ya que cada uno tiene diferentes características y contenido, en la medida que conozcamos su alcance la protección será mayor, ya que estamos sujetos a distintas consecuencias jurídicas, dependiendo del contrato que se trate.

Al manifestar la voluntad, ésta debe estar libre de cualquier vicio, sea error, dolo, violencia, incapacidad o lesión, con lo que se logrará llevar a cabo un acto jurídico pleno, ya que si se da cualquiera de los vicios, el contrato podrá caer en nulidad y por lo tanto sus efectos jurídicos podrán ser destruidos a menos que dichos vicios sean subsanados en términos de lo establecido por el Código Civil vigente.
Por lo que se puede asentar que: "El consentimiento de partes capacitadas para contratar, o sea, el acuerdo de voluntades competentes conscientes efectuado en la forma legal, es el elemento característico de todo contrato." (Planiol y Ripert, 1940, p.65). De acuerdo a lo anterior, el contrato debe realizarse con una voluntad consciente al momento de otorgarlo, con conocimiento del alcance jurídico que tendrá, de conformidad con las consecuencias del contrato que se trate, según lo plasmado de modo escrito, tácito o por el medio tecnológico o electrónico querido por las partas contratantes de acuerdo a la ley o código respectivo.

Hay que considerar el siguiente supuesto, si alguna persona celebra un contrato por medios tecnológicos, o electrónicos como puede ser el teléfono y si uno de los contratantes en el momento de realizarlo se encuentra bajo influencia del alcohol o el influjo de alguna droga o enervante, dicho acto jurídico contractual debe caer en nulidad, sin embargo hay que probar que al momento de celebrarlo, era incapaz uno de los sujetos, por encontrase alcoholizado, situación que se complica, por lo mismo es recomendable que al llevar a cabo el contrato, tengamos cierta seguridad de que el sujeto goza de capacidad plena, pues si existe alguna incertidumbre, lo conveniente es tomar medidas precautorias, tales como realizarle más preguntas, o indagaciones sobre su capacidad, si existe alguna duda, lo mejor es no llevarlo a cabo de dicho modo, sino de manera presencial o por cualquier otro medio o momento en que tengamos la certeza de que el contrato no caerá en nulidad. Como bien es sabido el contrato requiere del acuerdo de voluntades de modo pleno, que no tenga algún vicio del consentimiento que lo pueda nulificar.

Con el acuerdo de voluntades a que nos referimos, se forma el consentimiento, "El consentimiento es el acuerdo de voluntades constitutivo del contrato. Dos o más personas, por tanto dos voluntades, son necesarias, por lo menos, para que haya consentimiento $\mathrm{y}$, por ende, contrato. Pero el contrato puede existir entre un mayor número de personas como lo demuestran las sociedades." (Bonnecase, 1993, p. 794) 
A mayor abundamiento "Tal consentimiento tiene dos elementos fundamentales, a saber: la oferta o policitación, que viene siendo la primera declaración de voluntad del primer centro de interese o parte, y la aceptación, que viene siendo la otra declaración de voluntad de la parte o del otro centro de intereses." (Quintanilla, 1993, p.44). En dicho acuerdo de voluntades debe existir un interés jurídico lícito, para el caso que nos ocupa será la celebración de un contrato, cuyas características se encuentran en la ley o por lo que ambas partes quieran, para el supuesto de los contratos llamados atípicos por no estar regulados en la ley.

La voluntad en los contratantes es un elemento fundamental en el contrato, esto es "En el sujeto que contrata debe existir, necesariamente, Que la voluntad sea seria y precisa, ya que una promesa de simple juego o de broma, o en escena, o con fines didácticos, o un consentimiento simulado, o cuando vagamente se dice por ejemplo que se vende algo a menos del costo, no constituye la voluntad de obligarse;

(...) Que dicha voluntad se exteriorice, sea en forma expresa o tácita, (...) Que esa voluntad tenga un determinado contenido, (...) Puede afirmarse que nuestro Derecho más bien se orienta hacia el sistema de la voluntad interna declarada, ya que la escueta voluntad interna que no se exterioriza carece de relevancia jurídica, al igual de lo que ocurre con las "reservas mentales", en que existe una voluntad oculta que es contraria que es contraria a lo que se declara. "(Sánchez, 1980, p.1415).

Por lo que se puede afirmar que una voluntad a la que le falte, seriedad y sea ambigua o vaga, con la que el sujeto no tenga la intención de obligarse, podrá afectar al contrato si se llevaré a cabo, crearía confusiones en las partes contratantes, incluso muchas veces, podríamos estar queriendo hacer un contrato determinado, cuando en realidad estamos realizando otro, tal sería el caso de vender una cosa a un precio exageradamente bajo de su valor real, cuando en realidad estamos llevando a cabo un contrato de donación.
Como ya se ha mencionado la voluntad interna, el aspecto sicológico, debe coincidir con lo que queremos exteriorizar, pero claro está, no contraviniendo lo que establece el Código o ley aplicable al caso. Si la voluntad es exteriorizada, ya sea en forma escrita o tácita, por hechos que lo presuponen, deberán ser manifestados de modo claro y que no exista lugar a dudas del contrato que se quiere realizar, así como de su contenido, dicha voluntad formara el contrato en el momento en que exista acuerdo con otra voluntad, a través del otorgamiento del consentimiento y dando así la celebración del contrato respectivo, según sea lo que quieren ambos contratas y se cumplan con los requisitos que establece la ley, de acuerdo al contrato de que se trate, para el supuesto de un contrato típico o atípico si no estuviere regulado por la ley, en cuyo caso estaríamos conforme a la voluntad de las partes, y aplicaríamos las disposiciones legales más parecidas al contrato que estamos llevando a cabo, vgr.

En el contrato de suministro como puede ser de gas se aplican normas de la compraventa, ya que tiene características similares a la misma, así como lo que convengan los contratantes.

El acuerdo de voluntades, o consentimiento con el que se realiza un contrato produce efectos jurídicos, de acuerdo a la doctrina y en especial, "Colin y Capitant. El contrato o convenio es un acuerdo de dos o varias voluntades en vista de producir efectos jurídicos. Contratando, las partes pueden tener por fin, sea crear una relación de derecho: crear o transmitir un derecho real o dar nacimiento a obligaciones; sea modificar una relación preexistente; sea en fin extinguirla." (Borja, 1991, p.111)

Cabe mencionar que nuestro Código Civil Federal vigente, distingue entre el convenio y el contrato, siendo el primero el género y el segundo la especie. En el convenio se crean, transmiten, modifican, y extinguen obligaciones, entendiendo éste en sentido amplio y en el contrato se crean y transmiten derechos y obligaciones, en sentido estricto con relación al convenio. En ambas figuras se tienen consecuencias jurídicas. 


\section{Del sentido o contenido que puede tener el acuerdo de voluntades en un contrato}

Una vez expresada la voluntad a través de un contrato expreso, habrá que apegarse a lo que está escrito o plasmado en algún medio tecnológico, sin embargo cuando existen dudas en lo que quisieron decir las partes, tendremos que acudir a la interpretación, por lo que de conformidad con el Diccionario de la lengua española, interpretar lo define:

"Interpretación, (Del lat interpreratatio) onis. F. Acción y efecto de interpretar. Auténtica. Der. la que de una ley hace el mismo legislador(...) doctrinal. Der. La autorizada por la jurisprudencia de los tribunales.

Interpretar (Del lat.interprerari) tr. Explicar o declarar en sentido de una cosa, y principalmente el de textos faltos de claridad (...)3. Explicar acertadamente o no, acciones, dichos o secesos que pueden ser entendidos de diferentes modos (...)7. Concebir, ordenar o expresar de un modo personal. (Diccionario de la lengua Española, 2001, p. 834).

De conformidad con lo anterior y para el caso que nos ocupa, la interpretación busca desentrañar el sentido de lo manifestado en un contrato, por lo que habrá que acudir a la letra, es decir lo expresado textualmente y en caso de duda a la intención de los contratantes, éste último para lo previsto en los contratos de naturaleza civil. "Con la interpretación se pretende, como ya se dijo, la conservación del contrato y no la destrucción, y en el caso de las leyes se busca la aplicación justa y la solución de problemas concretos.

A través de la interpretación se determina la intención de las partes y, por tanto, el alcance y efectos del contrato, buscando que la solución sea apegada el derecho, y no incoherente e injusta." (Sanromán, 2018, p.93). $\mathrm{Al}$ interpretar un contrato y buscar la subsistencia del mismo, se debe hacer de un modo integral, es decir hay que analizar el contrato en relación a todo su contenido, y como ya se dijo en primer lugar a la letra y en el supuesto de que exista ambigüedad, a lo manifestado por los contratantes y de modo coherente.
Al interpretar un contrato debemos atender a los hechos manifestados y lo consentido por las partes, debe existir una armonía en lo que quisieron exteriorizar los contratantes y claro está apegarse a los términos jurídicos, aplicables en los códigos y leyes respectivas, ya que los contratos deben ir conforme a la ley.

Es importante señalar que las partes al manifestar el consentimiento en un contrato, deben tener una intención limpia, transparente, es decir que tengan buena fe, ésta es una valor fundamental en los contratos, sin la cual el contrato podría caer en nulidad; desde que existen los tratos previos de contratar, por parte de ambos sujetos, han de buscar llegar hasta el final de dicha operación, o acto jurídico, ya que si existiere un rompimiento intempestivo del mismo, por una conducta negativa o mal intencionada, el afectado podría llegar a demandar los daños y perjuicios que le causaré el otro contratante.

Con el objeto de evitar contrataciones ambiguas, que pudieren caer en nulidad o problemas legales e inclusos malos entendidos, que al momento de exteriorizarlas no llegan a comprenderse de manera clara y de acuerdo a una voluntad real de los sujetos, como parte de un interés jurídico de los contratantes; considero conveniente que el contrato sea elaborado por el especialista, es decir un licenciado en derecho, o en todo caso sea revisado y si no fuere así que por lo menos le de lectura un tercero que tenga algunos conocimientos jurídicos o de carreras afines a la ciencia jurídica, con el objeto de dar claridad a lo expresado en el contenido y con dicha prevención los problemas legales se podrían evitar, ya que de lo contrario, los contratos mal redactados o con imprecisiones podrían llegar hasta los tribunales, por lo que el litigio puede ser largo y desgastante para las partes litigantes en dicho proceso Sin lugar a dudas un buen contrato evitará dolores de cabeza futuro e innecesario.

\section{De acuerdo a todo lo anterior se concluye:}

- $\quad$ La voluntad es un elemento fundamental para manifestar el consentimiento, que debe ser libre, realizando con ello los distintos actos jurídicos y en especial los contratos como especie de los mismos, para producir efectos y consecuencias jurídicas.

ROBERTO-SANROMÁN, Aranda. La manifestación de la voluntad en los contratos como elemento fundamental para celebrarlos. Revista de Aplicaciones del Derecho. 2019 
- Manifestación, significa exteriorizar y para el caso de los contratos se refiere a que la voluntad interna, considerado también como el aspecto sicológico de una persona se expresa o lleva a cabo a través de actos o hechos que lo presuponen, indudablemente en este caso debe coincidir lo que pensamos de manera interna con lo que expresamos por cualquier medio.

- En el momento de exteriorizar la voluntad, debemos tener presente el enfoque jurídico del contrato que realizaremos, ya que cada uno tiene diferentes características y contenido, en la medida que conozcamos su alcance la protección será mayor.

Al momento de exteriorizar la voluntad debe existir libertad en el sujeto que lo hace, que para el caso del derecho civil se le conoce como autonomía de la voluntad, misma que no debe contravenir una ley.

- La gran mayoría de las relaciones jurídicas son de contenido patrimonial y dichos actos jurídicos, como son los contratos,- que se producen deben contar con elementos de existencia y requisitos de validez.

- La confianza que exista entre los contratantes al momento de manifestar la voluntad influye positivamente en la operación, ya que da salvaguarda a la buena fe de los que contratan.

Las partes contratantes no deben tener algún vicio del consentimiento, ya se trate de error, dolo, mala fe, lesión, violencia o incapacidad, ya que de lo contrario podría caer en nulidad el contrato.

La persona o sujeto debe tener capacidad mental para realizar el acto jurídico, llamado en el caso que nos ocupa, contrato y con ello realizar una obligación de dar o de hacer, dependiendo del tipo de contrato que se trate.
La voluntad interna del contratante debe coincidir con lo que pretende contratar, no deben existir contradicciones $\mathrm{o}$ intenciones que no son las realmente expresadas y que pudieran traer la nulidad del contrato.

- Al momento de exteriorizar un contrato debe llevarse a cabo de manera clara y comprensible para ambas partes, de acuerdo a la letra del contrato y en caso de duda estaremos a la voluntad de ambos contratantes, por lo que la interpretación del contrato buscará la conservación del mismo y no su destrucción.

- Desde el momento en que las partes manifiestan su voluntad, debe haber buena intención, es decir buena fe, misma que se verá reflejada en el contenido del texto del contrato o en la tecnología que se haya plasmado, ya que la buena fe en un contrato es fundamental para el mismo.

- La interpretación de un contrato debe ser integral y armónica con todo su contenido, un contrato no se debe interpretar de modo aislado de sus partes, ya que en la medida que sea bien interpretado, se logrará con ello lo querido por ambos contratantes.

- Es recomendable que al momento de elaborar un contrato, sea redactado por una especialista en derecho, o un conocedor de la ciencia jurídica, en la medida que el contrato sea claro y no contenga errores o ambigüedades, lo acordado por ambas partes será llevado a caobo de la mejor manera, para producir los efectos y consecuencias jurídicas deseadas.

\section{Referencias}

Bonnecase Julien. (1993). "Tratado Elemental de Derecho Civil." Tr. Enrique Figueroa Alfonzo. Editorial Harla. México.

Borja Soriano Manuel (1991) "Teoría General de las Obligaciones" $12^{\mathrm{a}}$ Edición. Editorial Porrúa S.A. México. 
Diccionario de la Lengua Española. (2001) Editorial Espasa Calpe, S.A. $21^{a}$ edición. T. I,II, España.

Diccionario Jurídico Mexicano. Voz: José Antonio Márquez González. (1991) "Voluntad" $4^{\mathrm{a}}$ Edición. T. IV. Editorial Porrúa y UNAM. México.

Galindo Garfias Ignacio. (1976) "Derecho civil". $2^{\mathrm{a}}$ Edición. Editorial Porrúa S.A. México.

Planiol Marcelo- Ripert Jorge. (1940) "Tratado práctico de derecho civil francés" t. VII. Editorial Cultural S.A. La Habana.

Quintanilla García Miguel Ángel. (1993) "Derecho de las Obligaciones." 3er Edición. Cárdenas Editor. México.

Sánchez Medal Ramón. (1980) “De los Contratos Civiles". $5^{\text {a }}$ edición. Editorial Porrúa, S.A. México.

Sanromán Aranda Roberto. (2018), Derecho de las Obligaciones. Editorial Tirant Loblanch.4a edición. México.

Trabucchi Alberto. (1967) "Instituciones de Derecho Civil". 15 $5^{\text {a }}$ Edición. Editorial. Revista de Derecho Privado. Madrid.

\section{Legislación consultada}

Código Civil Federal Vigente 